УДК 528.9

$10.17213 / 2075-2067-2020-6-211-216$

\title{
ОСНОВА СИСТЕМЫ \\ РАЦИОНАЛЬНОГО ИСПОЛЬЗОВАНИЯ ЗЕМЕЛЬНЫХ УЧАСТКОВ
}

\author{
(C) 2020 г. Н. Г. Овчинникова*, Н. В. Алиева ${ }^{\text {** }}$ \\ "Донской государственный технический университет, г. Ростов-на-Дону, Россия \\ **ННовчеркасский инженерно-мелиоративный институт \\ имени А. К. Кортунова (филиал), \\ Донской государственный аграрный университет, г. Новочеркасск, Россия
}

Целью исследования является анализ основных положений ращионального использования земельных участков с учетом принциипов рационального использования территорий посредством обеспечения управления земельным фондом для удовлетворения потребностей общества за счет свойств земли и повышения доходов от использования земельных ресурсов, а также сокращения расходов.

Методологическую базу исследования представляет анализ механизма государственной политики в сфере рационального использования земельных участков с иелью управления всем земельным фондом нашей страны для повышения уровня муниципальных образований на базе нормативных правовых документов.

Результаты исследования. Система раџионального использования земельных ресурсов направлена на регулирование земельно-имущественных отношений, необходима и обязательна в условиях рыночной экономики, обращена на учет публичных и частных интересов разных групп населения по сравнению с интересами государства. Закономерность современного периода формирования отечественной системы рачионального использования земельных участков состоит в том, что задачей совершенствования земельно-имущественных отношений в России является формирование оптимальной системь управления земельными ресурсами.

Перспективу исследования в соответствии с заявленной темой, посвященной исследованию аспектов рачионального использования земельных ресурсов, составляет анализ, направленный на формирование и развитие прочессов применения земельных ресурсов в границах муниципальных образований. В представленной статье на основе целевого использования земельных ресурсов обоснованы процессы их применения в границах муниципальных образований с иелью рачионального использования земельных участков путем регулирования земельно-имущественных отношений.

Ключевые слова: рациональное использование земельных участков; земельные ресурсы; категории земель; организация использования земли; перераспределение земель; формирование землепользования и обустройство; регулирование рыночного оборота земель. 


\title{
THE BASIS OF A RATIONAL USE SYSTEM LAND PLOTS
}

\author{
(C) 2020 N. G. Ovchinnikova*, N. V. Alieva**
}

\section{"Don State Technical University, Rostov-on-Don, Russia \\ ${ }^{* *}$ Novocherkassk Reclamation Engineering Institute named after A. K. Kortunov (branch), Donskoy State Agrarian University, Novocherkassk, Russia}

The aim of the study is to analyze the main provisions of the rational use of land plots, taking into account the principles of rational use of territories by ensuring the management of the land fund to meet the needs of society through the properties of the land and increasing income from the use of land resources, as well as reducing costs.

The methodological basis of the study is an analysis of the mechanism of state policy in the field of rational use of land plots in order to manage the entire land fund of our country in order to increase the level of municipalities on the basis of regulatory legal documents.

Research results. The system of rational use of land resources is aimed at regulating land and property relations, it is necessary and obligatory in a market economy, it is focused on taking into account the public and private interests of different groups of the population in comparison with the interests of the state. The regularity of the modern period of the formation of the domestic system for the rational use of land plots is that the task of improving land and property relations in Russia is to form an optimal system of land management.

The prospect of the study in accordance with the stated topic, aimed at researching aspects of the rational use of land resources, is an analysis aimed at the formation and development of processes for the use of land resources within the boundaries of municipalities. In the presented article, on the basis of the targeted use of land resources, the processes of their use within the boundaries of municipalities are substantiated with the aim of rational use of land plots by regulating land and property relations.

Key words: rational use of land plots; land resources; land categories; organization of land use; land redistribution; formation of land use and arrangement; regulation of market turnover of land.

Введение. Земельно-имущественные отношения - это неотъемлемая часть нашей жизни, а для них необходимо обеспечивать правопорядок с помощью контроля. Рациональное использование земельных участков основывается на том, что земля - всеобщее достояние России, а также один из главных резервов общественного формирования, именно поэтому управление и контроль за земельными участками и земельно-имущественными отношениями должен осуществляться в постоянном порядке и быть наиболее эффективным со стороны как государственных, так и муниципальных органов [1]. Задачей рационального использования земельных участков является развитие процессов применения земельных ресурсов в границах муниципальных образований. Объектом управления выступают земельные участки в установленных границах определенной площади и местоположения. Субъектами управления являются органы местного самоуправления.

Земельными ресурсами признаются земли, которые находятся в пределах границ Российской Федерации и могут быть использованы человеком для его деятельности и удовлетворения потребностей. Во многих странах земельные ресурсы законодательно регулируются. Первоначально земельные ресурсы классифицируются 
по их назначению [2]. Согласно Земельному кодексу РФ земли используются в соответствии с их целевым назначением и для них определен правовой режим. В соответствии со статьей 7 указанного кодекса выделяют семь основных категорий земель, указанных на рисунке 1.

При совокупном влиянии и государства в целом, и общества управление ресурсами будет обеспечено наиболее рационально и эффективно для использования в различных целях.

Основой системы целесообразного использования земельных участков служат указанные на рисунке 2 ее составляющие.

Так, в соответствии с рисунком 2 разберем подробно все составляющие системы рационального использования земельных участков. Объект представляет собой такой предмет, который требуется изучить, по данной тематике рассматриваются земельные участки, являющиеся комплексным природным ресурсом, и земельный фонд государства в целом страны, и отдельные части страны, города, административного района, субъектов РФ, муниципальных образований. Объ- ектом также выступают ограниченные части поверхности земли, которые можно указать на местности как индивидуально определенную вещь, то есть земельные участки, которые относятся к отдельным субъектам земельно-имущественных отношений и могут отличаться по виду применения и правовому режиму $[3,4]$.

Следующим рассматриваемым аспектом служит предмет управления. Он представляет собой набор процессов по организации использования земли, которая наиболее полно позволяет удовлетворить потребности его жителей в границах обусловленной территории. Субъекты управления можно разделить на следующие субъекты, которые осуществляют государственное, местное и внутрихозяйственное управление, начиная от государства как субъекта земельных отношений и завершая конкретным юридическим лицом или гражданином.

Целью рационального использования земельных участков в первую очередь является обеспечение управления земельного фонда для удовлетворения потребностей общества за счет свойств земли и повышения доходов

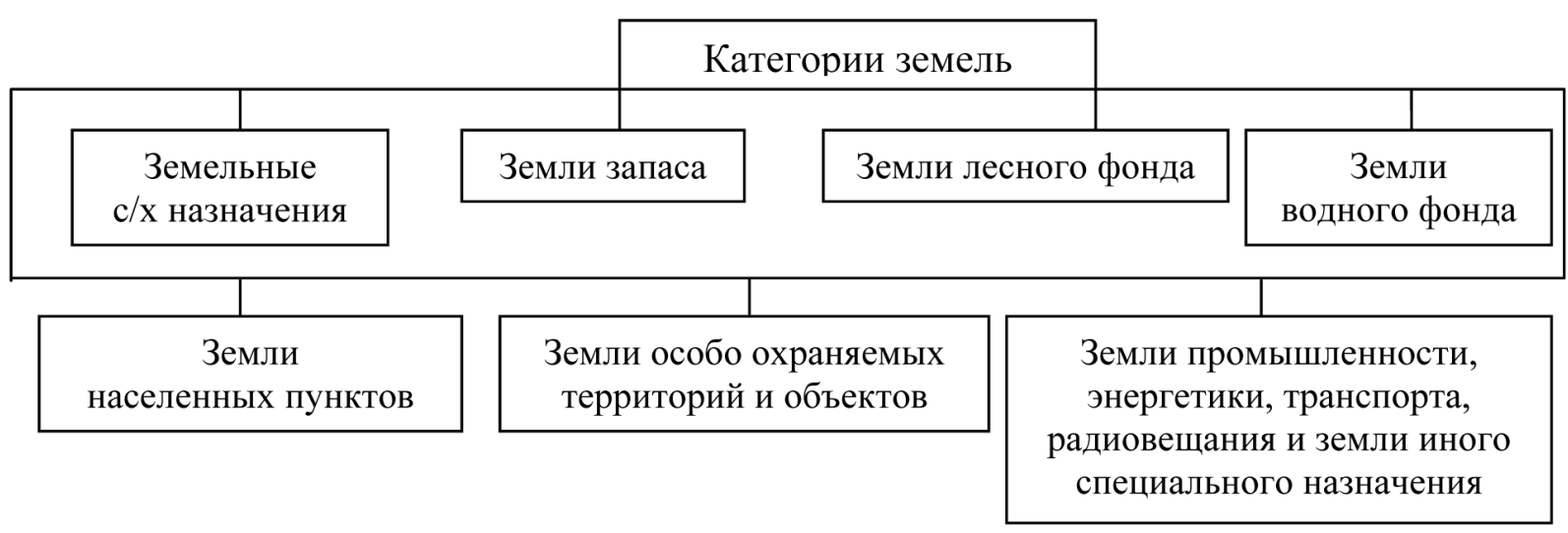

Рис. 1. Категории земель

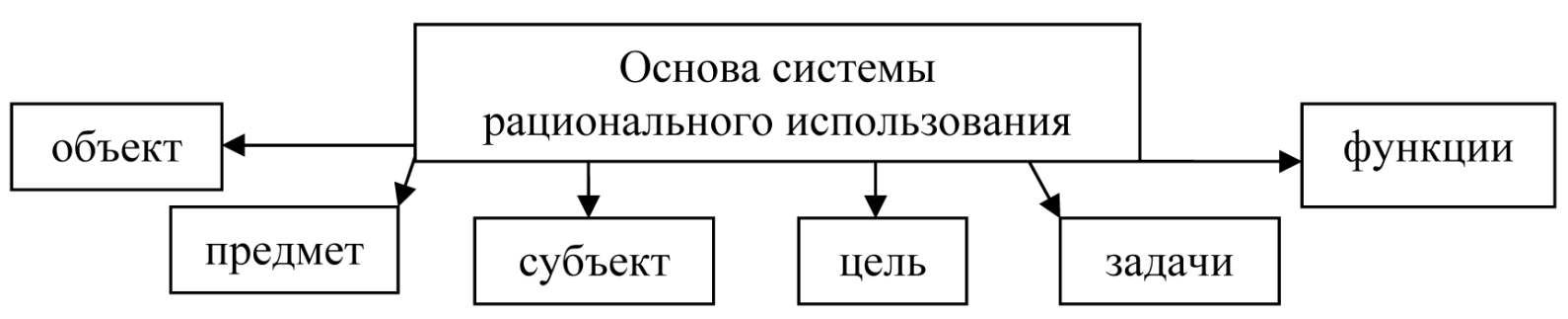

Рис. 2. Основа системы рационального использования 
от использования земельных ресурсов, а также сокращения расходов. Задачи правильного использования подразделяются на определенные уровни, то есть решение задач законодательных и исполнительных органов власти, регулирующих земельные отношения и устанавливающих общую и основную стратегию землепользования, нормотворчества, правоохранительной деятельности. Назначения осуществляются субъектами управления и имеют значительные различия по отношению к проблемам обеспечения жизнедеятельности конкретных отраслей, регионов и перспектив их развития [5]. В связи с этим можно выделить этапы функций рационального использования земельных участков. Вначале обеспечивается сбор и обработка данных об объекте, подлежащем контролю. Данный этап подразделяется на группы, к которым можно отнести ведение земельного кадастра и мониторинга земель, их инвентаризацию, полевые обследования, создание и ведение геоинформационных систем. Далее обеспечивается процесс принятия наилучших решений, к которым можно отнести прогнозирование, планирование и проектирование применения земель. Чтобы реализовать установленные решения, необходимо государственное перераспределение земель, формирование землепользования и обустройство, а также регулирование рыночного оборота земель. Еще одним этапом является контроль за исполнением выработанного процесса, что включает в себя проверку использования земель и соблюдения земельного законодательства, разрешение земельных споров [6].

Главной задачей совершенствования земельно-имущественных отношений в России является формирование оптимальной системы управления земельными ресурсами. Управление земельными участками носит комплексный характер, поскольку затрагивает интересы большинства субъектов земельноимущественных отношений, что является основанием для органов управления обеспечения упорядоченного и систематизированного подхода к созданию процесса использования и охраны земельных участков так, чтобы увязывать решения организационно-технологических условий с вероятными эколого-экономическими результатами.
Заключение. Можно сказать, что общие экономические, экологические и социальные законы служат основой для процесса использования и развития земельных участков, и эти законы свойственны любой социальноэкономической структуре общества, а также ядром для управления являются законы природы. В нашем государстве любая деятельность должна быть законна во всех областях, особенно явно это прослеживается в земельных правоотношениях, поскольку земельные ресурсы - один из элементов нормального существования людей в современном мире.

\section{Литература}

1. Медведков Д. А., Овчинникова Н.Г. Комплексное и устойчивое развитие застроенной территории: опыт, проблемы и пути их решения // В книге: Организационно-экономические проблемы регионального развития в современных условиях. Материалы научно-практической конференции молодых ученых, аспирантов и студентов. - 2018. - С. 204-206.

2. Овчинникова Н.Г. Анализ использования земельных ресурсов на территории Ростовской области // В сборнике: Проблемы рационального природопользования и пути их решения. Сборник материалов Всероссийской научно-практической конференции, посвященной 45-летию ФГБОУ ВО «ДГТУ». 2018. - C. 245-249.

3. Ovchinnikova N. G. Analysis of territorial planning and prospects for further development of urban districts and settlements in Rostov region // In the book: MATEC Web of Conferences. - 2017. - P. 1004.

4. Русских А.В., Овчинникова Н.Г. Значимость документов территориального планирования муниципального образования для ведения ЕГРН // Электронный сетевой политематический журнал «Научные труды КубГТУ»». — 2017. — №4. - C. 285-289.

5. Овчинникова Н. Г., Шумкова Е.С. Учетно-регистрационный процесс в системе управления земельными ресурсами // Экономика и экология территориальных образований. - 2016. - №2. - С. 125-129.

6. Алиева Н.В. Развитие экономических методов регулирования земельных отношений // Вестник Южно-Российского государственного технического университета (Ново- 
черкасского политехнического института). Серия: Социально-экономические науки. 2016. — №4. - С. 43-46.

\section{References}

1. Medvedkov D.A., Ovchinnikova N.G. Kom-pleksnoe i ustojchivoe razvitie zastroennoj territorii: opyt, problemy i puti ih reshenija [Integrated and sustainable development of the built-up area: experience, problems and ways to solve them] // V knige: Organizacionno-jekonomicheskie problemy regional'nogo razvitija v sovremennyh uslovijah. Materialy nauchnoprakticheskoj konferencii molodyh uchenyh, aspirantov i studentov [In the book: Organizational and economic problems of regional development in modern conditions. Materials of the scientific and practical conference of young scientists, postgraduates and students]. — 2018. Pp. 204-206.

2. Ovchinnikova N. G. Analiz ispol'zovanija zemel'nyh resursov na territorii Rostovskoj oblasti [Analysis of the use of land resources on the territory of the Rostov region] // V sbornike: Problemy racional'nogo prirodopol'zovanija i puti ih reshenija. Sbornik materialov Vserossijskoj nauchno-prakticheskoj konferencii, posvjashhennoj 45-letiju FGBOU VO «DGTU» [In the book: problems of rational use and ways to solve them. Collection of materials of the all-Russian scientific and practical conference dedicated to the 45th anniversary of DSTU]. 2018. - Pp. 245-249.
3. Ovchinnikova N.G. Analysis of territorial planning and prospects for further development of urban districts and settlements in Rostov region // In the book: MATEC Web of Conferences. - 2017. - Pp. 1004.

4. Russkih A. V., Ovchinnikova N. G. Znachimost' dokumentov territorial'nogo planirovanija municipal'nogo obrazovanija dlja vedenija EGRN [Significance of territorial planning documents of the municipality for conducting the unified state register of Russian education]// Jelektronnyj setevoj politematicheskij zhurnal «Nauchnye trudy Kub-GTU» [Electronic network polythematic journal «Scientific works of KUB-GTU»]. - 2017. — №4. - Pp. 285-289.

5. Ovchinnikova N.G., Shumkova E.S. Uchetno-registracionnyj process $\mathrm{v}$ sisteme upravlenija zemel'nymi resursami [Accounting and registration process in the land management system]// Jekonomika i jekologija territorial'nyh obrazovanij [Economics and ecology of territorial entities]. 2016. 一 №2. - Pp. 125-129.

6. Alieva N.V. Razvitie jekonomicheskih metodov regulirovanija zemel'nyh otnoshenij [Development of economic methods for regulating land relations] // Vestnik Juzhno-Rossijskogo gosudarstvennogo tehnicheskogo universiteta (Novocherkasskogo politehnicheskogo instituta). Serija: Social'no-jekonomicheskie nauki [Bulletin of the South Russian state technical University (Novocherkassk Polytechnic Institute). Series: Social and economic Sciences]. 2016. — №4. — Pp. 43-46. 


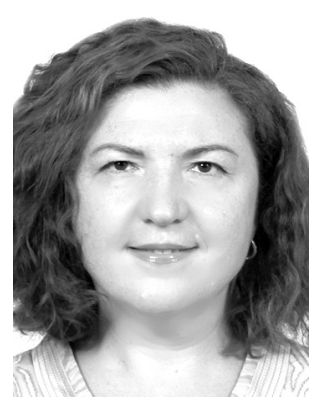

Овчинникова Наталья Геннадьевна - кандидат экономических наук, доцент Донского государственного технического университета.

Ovchinnikova Natalya Gennadyevna - Candidate of Economic Sciences, Associate Professor, Don State Technical University.

344022, г. Ростов-на-Дону, пл. Гагарина, 1

1 Gagarin sq., 344022, Rostov-on-Don, Russia

E-mail: natali281280@yandex.ru

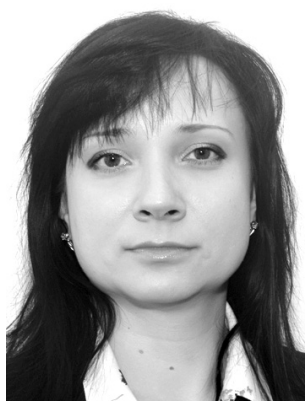

Алиева Наталья Владимировна - кандидат экономических наук, доцент Новочеркасского инженерно-мелиоративного института имени А. К. Кортунова (филиала) Донского государственного аграрного университета.

Alieva Natalya Vladimirovna - Candidate of Economic Sciences, Associate Professor, Novocherkassk Reclamation Engineering Institute named after A. K. Kortunov (branch), Donskoy State Agrarian University.

346400, г. Новочеркасск, ул. Пушкинская, 111

111 Pushkinskaya st., 346400, Novocherkassk, Russia

E-mail: natali281280@yandex.ru 